\title{
Functional Postures Assumed by Elderly People on Daily Activities - A Pilot Study for Interior Home Design
}

\author{
Carla P. GUIMARÃES ${ }^{a}$, Flavia C.H. PASTURA ${ }^{a}$, Maria C.P. ZAMBERLAN ${ }^{a}$, \\ Gloria L. CID $^{a}$, Denise BATISTA ${ }^{a}$, P. STREIT ${ }^{a}$, Mariana FRAGA ${ }^{a}$, Jose OLIVEIRA ${ }^{a}$, \\ Marcelo P. FERREIRA ${ }^{a}$, V. SANTOS ${ }^{a, b}$ \\ ${ }^{\text {a }}$ National Institute of Technology (INT), Rio de Janeiro, Brazil; \\ ${ }^{\text {b }}$ PUC RIO, Departamento de Engenharia Industrial, Rio de Janeiro, Brazil \\ http://dx.doi.org/10.15221/13.476
}

\begin{abstract}
The main purpose of this study was to scan elderly people in home activities postures selected according to frequency, difficulty in maintaining and safety, in order to create a functional postures database to be applied on interior home design. In the last 10 years the elderly proportion in the Brazilian population has had a marked growth. The percentage of people over 60 years increased from $8.6 \%$ in 2000 to $10.8 \%$ in 2010 . In this context, falls are one of the most serious consequences of aging recognized as an important public health problem due to incidence, to health complications and to high assistance cost. Physical dependency and psychological troubles are common consequences for elderly people after home accidents due to loss of independence and loss of self esteem. The functional postures database will be used to study interior home lay-outs in order to improve safety and avoid hazardous workload postures at home. In the first phase of the study 10 women and 01 man were interviewed and scanned simulating daily activities postures. On a second phase elderly people movements' will be captured through motion capture technology in home environments. Partial result analysis indicated the adoption of common postures, for example: on getting something from the floor, a forward trunk bending posture was mostly performed, instead of a knee flexion posture. The importance of this study is in understanding how to implement new interior lay-out design guidelines and to aid prevention programs in nursing-home institutions aiming to improve the elderly population's quality of life and safety. This pilot study is part of two research studies supported by FAPERJ - Rio de Janeiro Research Support Agency.
\end{abstract}

Keywords: elderly people, functional postures, 3D body scan, home interior design

\section{Introduction}

The elderly proportion in the Brazilian population has had a marked growth in the last 10 years. The percentage of people over 60 years increased from $8.6 \%$ in 2000 to $10.8 \%$ in 2010. In 78 cities of Brazil this portion of citizens already represents $20 \%$ of the total population. In this context, falls are one of the most serious consequences of the aging process, being recognized as an important public health problem due to their incidence, to health complications and to the high assistance cost. In other words falls are a major source of disability in older people and are highly associated with postural instability [3]. This is a matter of concern with the elderly as it can lead to physical handicap and loss of independence. Research conducted in Brazil and other countries refers that falls are more frequent among institutionalized elderly people and have multiple causes [2]. A study conducted with elderly people in Fortaleza city/Brazil pointed out that the main falling causes $(57 \%)$ were related to inadequate home environments and among the factors related to domestic environment, the most often cited was the existence of slippery surfaces (33\%). The most common consequence of falls was fracture, indicated by $43 \%$ of the elderly; radius fracture being the most frequent one (56\%). Common consequences for elderly people after home accidents may be increased physical dependency and wide range of psychological troubles due to loss of independence and self-esteem. Aches and pains caused by chronic muscle tension and joint stiffness are also a common complaint. Cataracts, presbyopia (loss of the ability to focus on close objects) and age-related macular degeneration limit visual acuity as we get older. In order to compensate for these difficulties, it is important to modify work and home environmental factors to make things easier to see. Most symptoms associated with aging that are relevant to ergonomics can either be prevented or at least successfully accommodated, so they need not to become debilitating. By being aware of common changes in the body, people can modify their diet, exercise, and physical environments to carry comfortable and active lives. 
On daily tasks as cooking and cleaning elderly people face physical limitations. For that reason to reduce tiredness in daily task performing it is important that, for instance, the kitchen be designed accordingly to their physical and physiological characteristics. Architects, designers and engineers should look into the requirements of the aging population in providing ergonomic home design [5] Old people are vulnerable to accidents, since the senses of direction, vision, touch, hearing and smell decrease with age. Physical abilities become limited, making the execution of common tasks more difficult. Through the use of ergonomic analysis it was possible to observe many problems concerning the activities performed in the kitchen [5]

As stated by official Brazilian population demographic surveys, the Brazilian population is witnessing an irreversible population aging. The resulting physical and mental change and limitations, bring about a new population profile, which generates changes and challenges in its demands.

The main research approach is in the occupation and use of the domestic space with safety and comfort. The main purpose of this study was to scan elderly people in daily activities postures selected according to frequency, difficulty and safety in home situations, in order to create a functional postures databank to be applied with interior home design.

\section{Methods}

On this pilot study ten healthy elderly people were first selected from a sample defined by CEPE (Rio de Janeiro State Elderly Research Center). Those people were invited to go to the Ergonomics Laboratory of the National Institute of Technology (INT) where they were interviewed in order to understand their limitations and difficulties in daily tasks at home. After the interview analysis some functional postures were selected, as for example: getting objects from below knee height and above shoulder height. Each elderly person was invited to enter into WBX body scanner and assume the functional postures selected. Only one elderly person was scanned with and without the walking stick. Each scan was treated using the process of retopology. Afterwards they were superimposed to compare the differences in posture between them and to compute the occupied space in the three planes of motion. [1,4]

\section{Results}

It is important to state that this research is a pilot study and the researchers are still testing the methodology.

\section{A - Posture 1 - getting objects above shoulder height}



Fig. 1 and 2 - Functional posture simulating getting something above shoulder height frontal and sagittal plane 


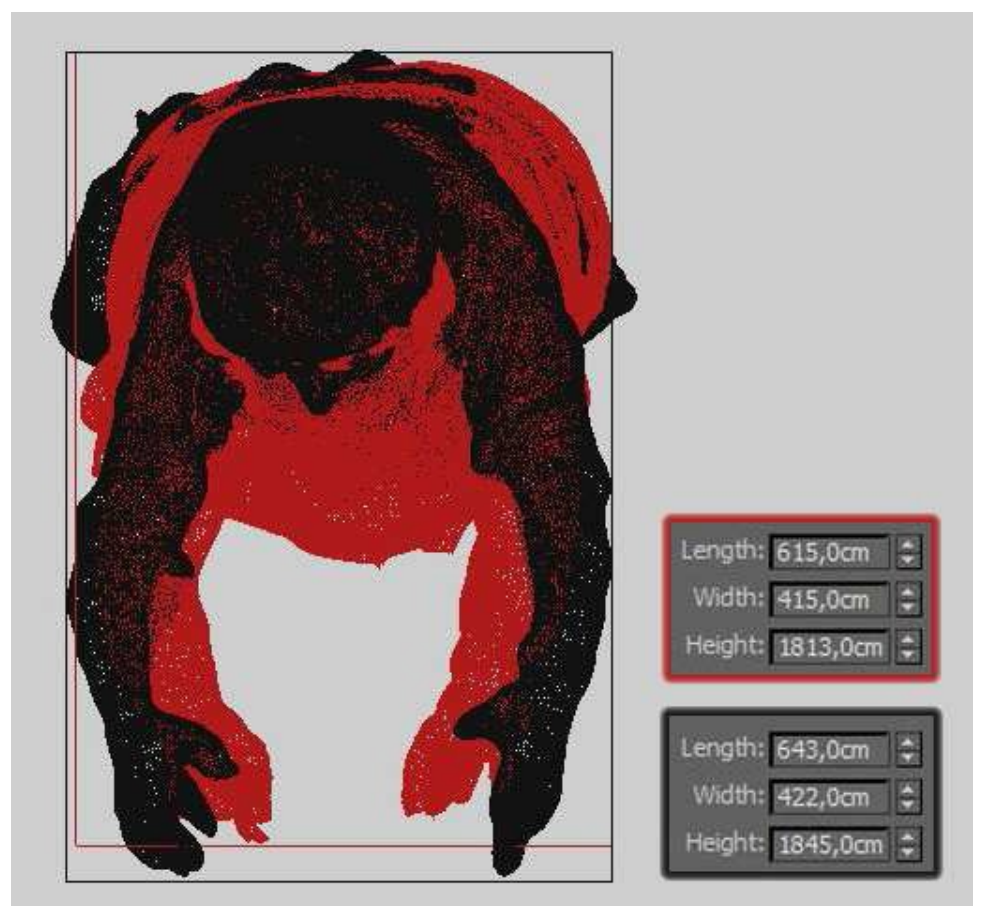

Fig. 3 - Functional posture simulating getting something above shoulder height transversal plane.

The first analysis comparing the postures presented on fig. 1, 2 and 3 showed that they try not to lean forward in order not to lose balance. They stretched their arms, but most of them present difficulties to sustain that movement.

\section{B - Posture 2 - simulation of getting objects below knee height}

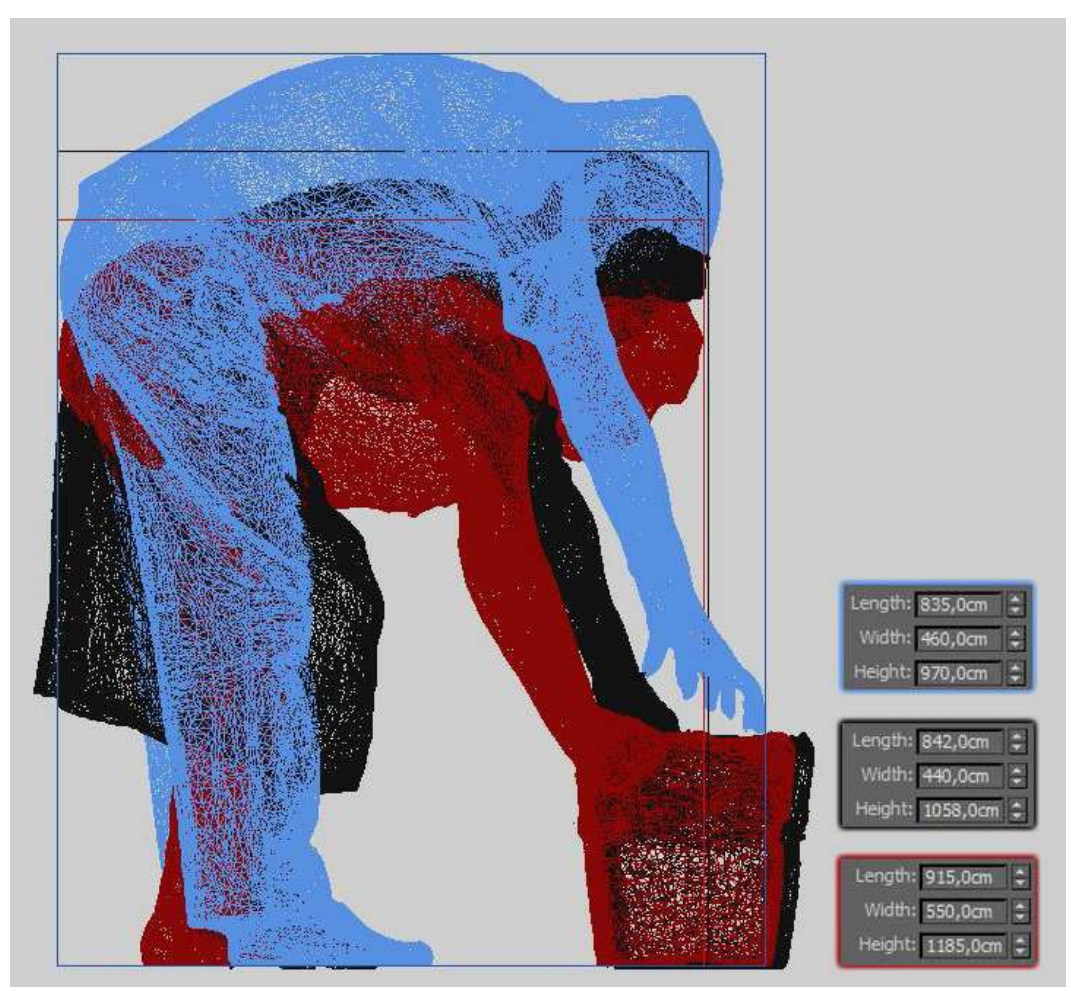

Fig. 4 - Functional posture simulating getting something below knee height sagittal plane. 


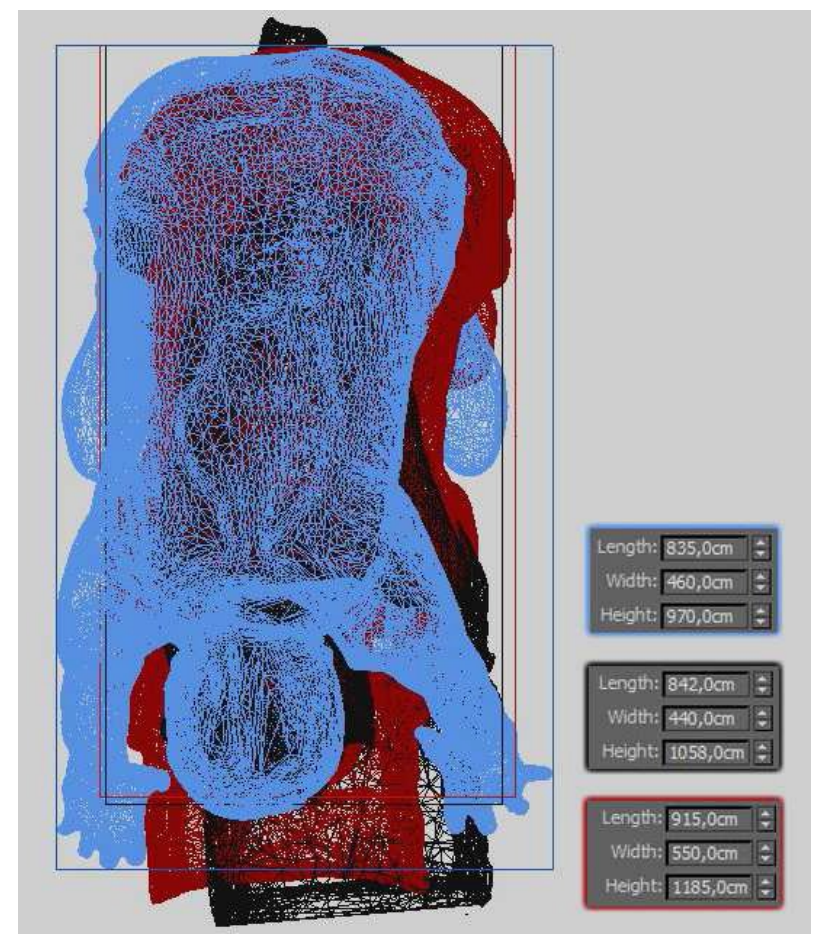

Fig. 5 - Functional posture simulating getting something below knee height transversal plane.

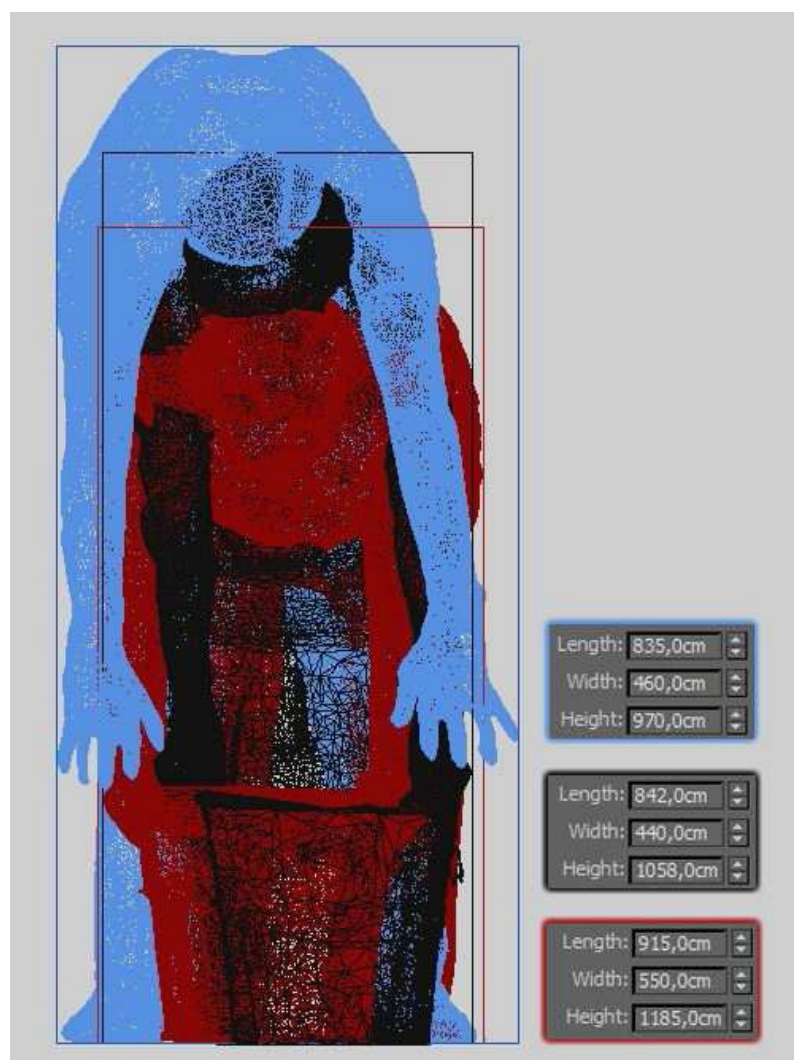

Fig. 6 - Functional posture simulating getting something below knee height frontal plane.

The first analysis comparing the postures presented on fig. 4, 5 and 6 showed that they try not to flex the knee in order to get something near the floor. Those postures were most performed by trunk movement and as consequences there were back pain and dizzy feeling complaints. Most of them presented difficulties to sustain that movement. 


\section{C - Posture 3 - Elderly person using a walking stick}

The first analysis comparing the use and not use of the walking stick (see fig. 7 and 8 ) showed that the elderly person changed her posture assuming a leaning-forward posture and a trunk lateral inclination posture when using the walking stick. The person not only changed her posture but also changed the occupied space.
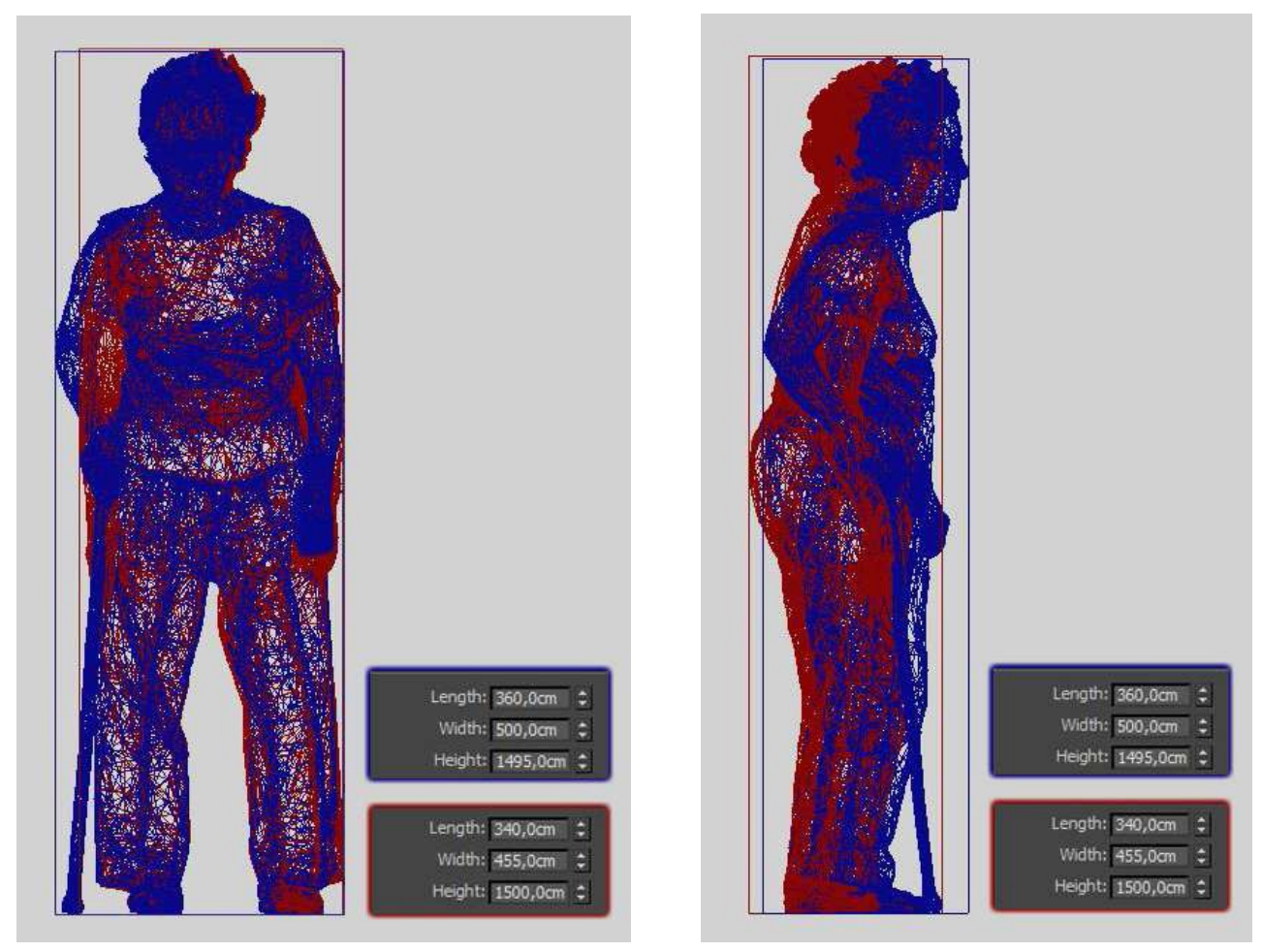

Fig. 7 and 8 - Posture with and without the use of the walking stick.

\section{Conclusion}

This pilot study is part of a larger project conducted by the Ergonomics Laboratory of INT and the Center for Studies and Research on Aging of Rio de Janeiro (CEPE). The preliminary analysis showed the importance of creating an elderly functional postures database that could help designers to understand and design homes better adapted to elderly conditions.

\section{References}

1. Guimarães, C.P., Cid, G.L., Zamberlan, M.C., Santos, V., Pastura, F.C.H., Oliveira, J. Franca, G. and Paranhos, A.G. (2013) Occupational safety and Hygiene, "Ergonomics Analysis applied to chemical laboratories on an oil and gas industry", Vol 1, pp. 33-336, CRC Press London UK

2. Lojudice, D. C., Laprega M. R., Rodrigues, R.A.P. and Rodrigues Júnior, A.L. (2010) "Quedas de idosos institucionalizados: ocorrência e fatores associados" Rev. Bras. Geriatr. Gerontol, Rio de Janeiro, 2010; 13(3):403-412

3. Maia, B.C., Viana, P. S., Arantes, P. M. M. and Alencar, M. A. (2011) "Consequências das quedas em idosos vivendo na comunidade: revisão sistemática", Rev. Bras. Geriatr. Gerontol. v.14 n.2 Rio de Janeiro

4. Santos, V., Guimaraes, C.P., Cid, G.L. and Paranhos, A.G. (2012) "DHM in Human-Centered Product Design: A Case-study on Public Transport Vehicle", Work (Reading, MA) 2012 vol 41

5. Taha, Z. and Sulaiman, R. (2010) The Ergonomics Study of Elderly Cooking Space: Kitchen Triangle The 11th Asia Pacific Industrial Engineering and Management Systems Conference The 14th Asia Pacific Regional Meeting of International Foundation for Production Research, Melaka, 7 to 10 December 